\title{
Impact of Village Resistance Values on Simulating Results of Flood Routing in Floodplains
}

\author{
Fengde Zhang $^{1}$ and Xiaolei Zhang $^{2}$ \\ ${ }^{1}$ Sanjiang Engineering Construction Management Bureau of Heilongjiang Province, Haerbin, China \\ ${ }^{2}$ State Key Laboratory of Water Resources and Hydropower Engineering Science, Wuhan University, Wuhan, China
}

\begin{abstract}
D hydrodynamic model using unstructured triangular meshes was first established. And the model was verified against the analytical solutions and experimental data of dam-break flows in laboratory. Finally, the model was employed to preliminarily simulate inundated floods routing in Lankao and Dongming floodplains of Lower Yellow River (LYR), and the impact of roughness value in village regions on modeling results was thoroughly analyzed. The results show that the water depth for hollowing village region was largest, and the maximum value of water depth increasing was about $0.57 \mathrm{~m}$. Different roughness values in village region had significant impact on flood routing near village. To be specific, the water depth of $n=0.12$ was $0.25 \mathrm{~m}$ larger than that of $n=0.06$, the corresponding flow velocity decreased by $0.24 \mathrm{~m} / \mathrm{s}$.
\end{abstract}

\section{Introduction}

Floodplain is the important part of river, as well as habitat for human life and production. Once the overbank floods happen, the floodplain will become the natural flood detention zone, playing a role of flood detention, but it will also cause some degree of flooding, resulting in the catastrophic consequences, such as loss of people's lives and property losses. In order to assess flood risk in floodplains, the 2-D hydrodynamic model is often used to simulate the process of flood routing. The 2-D hydrodynamic from Huayuankou to Jiahetan based on the finite volume method of unstructured mesh is established, and the water-blocking buildings such as channel and road are treated with the internal boundary conditions [1]. A numerical model coupled by 1-D and 2-D numerical models based on the finite volume method is developed to simulate flood routing in Daqing River floodplains [2]. A 2-D model based on alternating direction implicit method is built, which is used to simulate flood routing in the reaches from Jiahetan to Gaocun of LYR [3]. The sediment transport and riverbed deformation process aren't generally considered by foreign researchers while simulating flood routing in floodplains, and the diffusion wave model is mostly adopted [4,5]. 2-D shallow water equations are used to simulate flood routing in Toce River [6]. The process of flood routing in the floodplains of Severn River is simulated using the diffusion wave model based on the high accuracy digital terrain elevation [7]. The above research results mostly focus on the development of mathematical model and flood routing simulation in the floodplain.
There are many villages in floodplains, and village resistance has the important effect on overbank flood routing. But now there are fewer researches on the influence of different village resistance values on flood routing process. In this paper a 2-D hydrodynamic model using unstructured triangular meshes was employed to simulate flood routing in the typical floodplains of LYR, and the impact of village resistance on modeling results was thoroughly analyzed.

\section{The mathematical model}

\subsection{Governing equations}

The process of flood routing in natural rivers and on floodplains can be described by a set of shallow water equations for flows over a horizontal plane. The governing equations used in this model can be written in the following conservative form:

$$
\frac{\partial \mathbf{U}}{\partial t}+\frac{\partial \mathbf{F}}{\partial x}+\frac{\partial \mathbf{M}}{\partial y}=\frac{\partial \mathbf{F}}{\partial x}+\frac{\partial \mathbf{M}}{\partial y}+\mathbf{S}
$$

Where $\mathbf{U}$ is vector of conserved variable; $\mathbf{F}$ and $\mathbf{M}$ is convective mass and momentum flux vector, respectively; $\mathbf{F}$ and $\mathbf{M}$ is diffusive vector related to the turbulent stress in the $x$ and $y$ direction, respectively; $\mathbf{S}$ is source term including bed friction and bed slope; and $t$ is time. The above terms can be expressed in detail as:

$$
\mathbf{U}=\left[\begin{array}{c}
h \\
h u \\
h v
\end{array}\right], \quad \mathbf{F}=\left[\begin{array}{c}
h u \\
h u^{2}+\frac{1}{2} g h^{2} \\
h u v
\end{array}\right], \quad \mathbf{M}=\left[\begin{array}{c}
h v \\
h u v \\
h v^{2}+\frac{1}{2} g h^{2}
\end{array}\right], \quad \mathbf{F}=\left[\begin{array}{c}
0 \\
\tau_{x x} \\
\tau_{y x}
\end{array}\right],
$$




$$
\mathbf{M}=\left[\begin{array}{c}
0 \\
\tau_{x y} \\
\tau_{y y}
\end{array}\right] \text {, and } \mathbf{S}=\left[\begin{array}{c}
q_{s} \\
h f v+g h\left(S_{b x}-S_{f x}\right) \\
-h f u+g h\left(S_{b y}-S_{f y}\right)
\end{array}\right]
$$

Where $u, v$ is respectively depth-averaged velocity in $x$ and $y$ direction; $h$ is total water depth; $q_{s}$ is source (or sink) discharge per area; $g$ is gravitational acceleration; $f$ is Coriolis acceleration due to the Earth's rotation; $S_{b x}$ and $S_{b y}$ is respectively bed slope in $x$ and $y$ direction; $S_{f x}$ and $S_{f y}$ is friction slope in $x$ and $y$ direction, respectively; and $\tau_{x x}, \tau_{x y}, \tau_{y x}$ and $\tau_{y y}$ are turbulent shear stresses.

\subsection{Numerical solution}

The governing equations are solved using the finite volume method based on an unstructured triangular mesh in the model. A cell-centred finite volume method is adopted in this model, in which the average values of the conserved variables are stored at the centre of each cell, with the three edges of each cell defining the interface of a triangular control volume. At an interface between two neighbouring cells, the calculation of flow fluxes can be treated as a locally one-dimensional problem in the direction normal to the interface, thus the fluxes can be obtained by an approximate Riemann solver. In the current model, a Roe's approximate Riemann solver, with the scheme of MUSCL [8] is employed for evaluating the normal fluxes across the cell interface, with a procedure of predictor-corrector time stepping being used to provide second-order accuracy in both time and space. Furthermore, a refined procedure for treating wetting and drying fronts is used in the model, and this method has been shown to be effective in simulating the wetting and drying processes due to rapid flooding. In addition, a small value of minimum water depth is usually used to simulate the evolution of wetting and drying fronts, and the specification of a minimum water depth also depends on the grid size, time step and the topographical features of a study area.

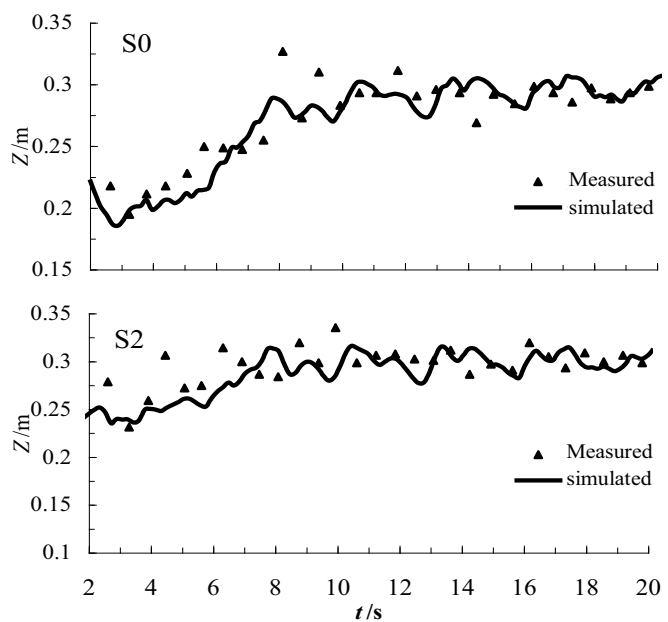

Figure 3. Comparisons between the calculated and observed water level hydrographs.
The above model is used to simulate a dam-break flow in a pool with a pyramidal obstacle, and the hydraulics model test is completed by Brufau in CITEEC laboratory

\subsection{Model validation}

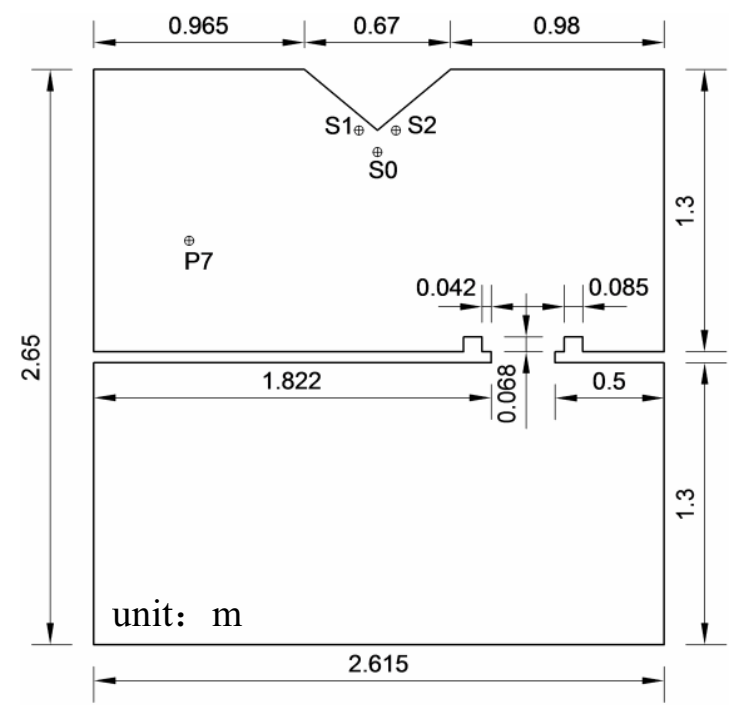

Figure 1. Sketch of a dam-break flow test.

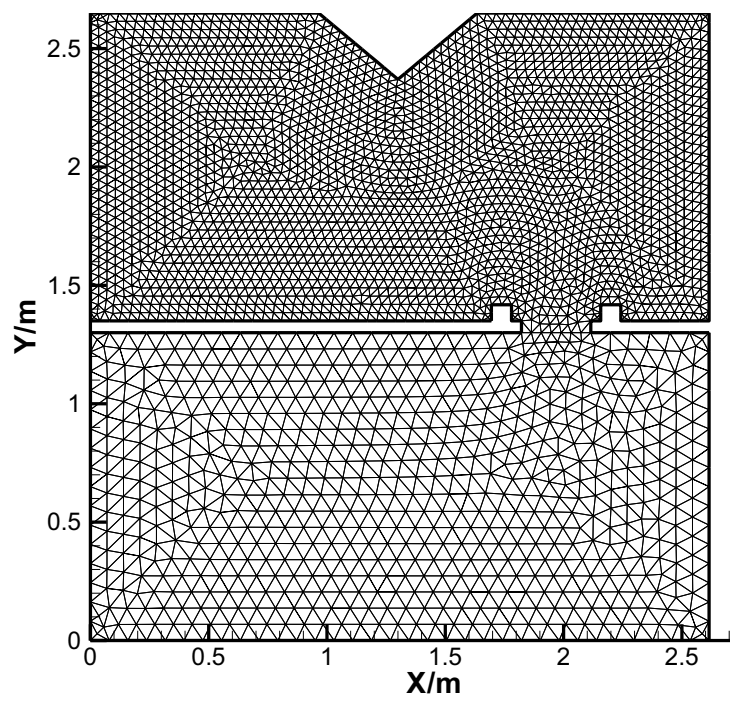

Figure 2. Computational grids.
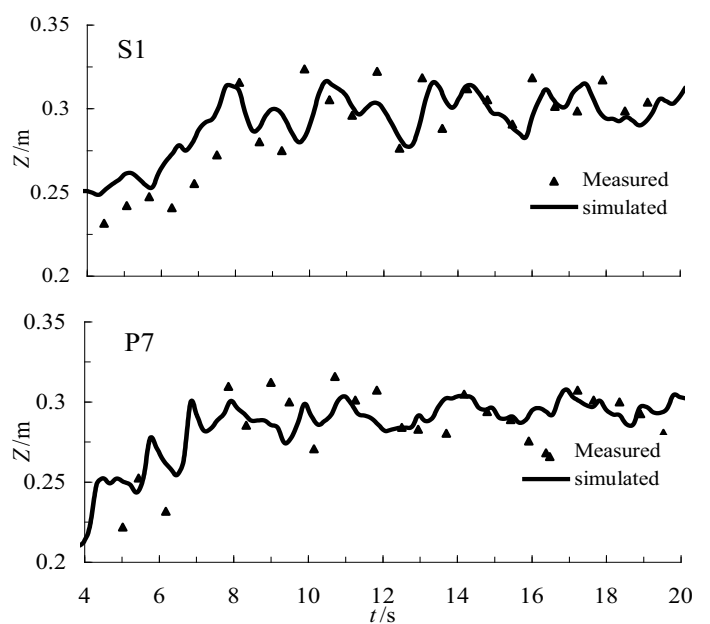

of Spain [9]. The model test can be used to test the capacity of model on better capturing the shock wave in dam-break floods. This model experiment is done in a 
closed tank, which is divided into two parts by a solid wall, setting a sluice gate in the non-symmetric position of solid wall, and the width of gate is $0.293 \mathrm{~m}$, the plane layout of model is shown in Figure 1. The closed pool's bottom is flat. The initial water depth in the pool upstream is $0.5 \mathrm{~m}$, and the water depth in the pool downstream is $0.1 \mathrm{~m}$. If the gate is removed suddenly, dam-break flow will happen. The whole calculation domain is composed of 24133 triangle meshes, and the computational grid is shown in Figure 2. The surrounding walls of pool and partition are concrete and solid boundary, and the corresponding roughness value is 0.018 . The minimum water depth is $0.001 \mathrm{~m}$, and time step is $0.025 \mathrm{~s}$. The change processes of water level at different locations are given. The comparison results show that close agreement is obtained between the model predictions and the observed data. So the model can simulate the routing process of unsteady flow well in complicated boundary conditions.

\section{Simulation of flood routing in typical floodplains of LYR}

\subsection{Simulation domain and calculation conditions}

Lankao and Dongming floodplains in the LYR are chosen as the simulation domain, covering area of $193 \mathrm{~km}^{2}$. The minimum width is $1.2 \mathrm{~km}$, and the maximum width is $11.2 \mathrm{~km}$. There exist lots of villages in the floodplain, which have obvious effects on overbank flood routing. Sketch of Lankao and Dongming floodplains are shown in Figure 4.

The flood of August 1982 is selected for simulation, which is the largest flood in the LYR since the Sanmenxia project has been built. The peak discharge at Jahetan station is $14500 \mathrm{~m}^{3} / \mathrm{s}$. In present study the process of overbank flood routing is focused, considering the recent bankfull discharge in the reaches has been restored to $7000 \mathrm{~m}^{3} / \mathrm{s}$, so the bankfull discharge should be subtracted from the overall discharge, and the final calculated flood process is illustrated in Figure 5. In order to reflect the effects of village resistance on simulation results, village regions are center-hollowed, and the roughness values are set to $0.06,0.08,0.10$ and 0.12 , respectively. Then the verified model is employed to simulate the overbank flood routing and the effects of different roughness values on calculation results are further analyzed.

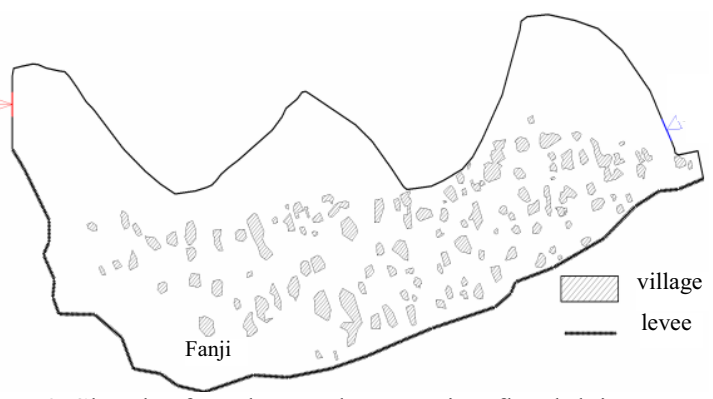

Figure 4. Sketch of Lankao and Dongming floodplains.

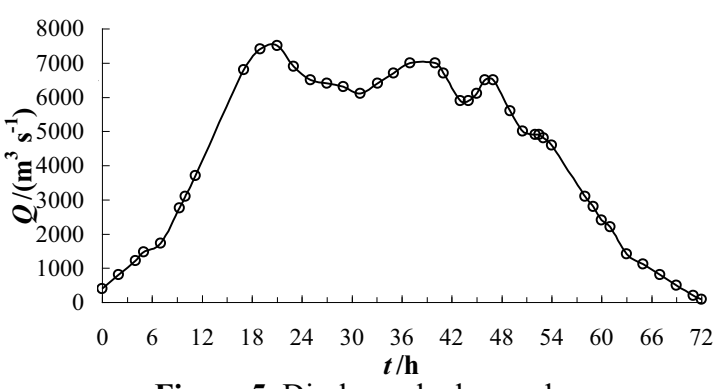

Figure 5. Discharge hydrograph.

\subsection{Effect of village roughness coefficient}

In order to reflect on the result of village resistance simulation, take Fanji village for an example, four representative points near the village are chosen. Local grid structure and the locations of measured points are shown in Figure 6.

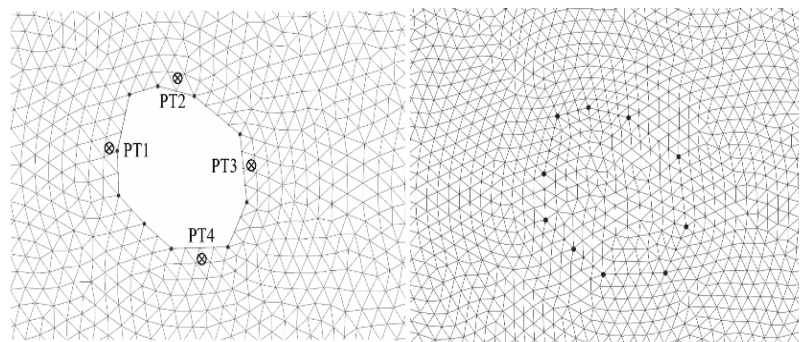

Figure 6. Local unstructured triangular grids near village and observation sites.

The analysis on results of water depth and flow velocity under different roughness value conditions at PT3 shows that the water depth under the scenario of center-hollowed village region is largest, which is 0.47 to $0.57 \mathrm{~m}$ larger than that under different roughness values conditions.

For different conditions of roughness values in village region, the water depth of each measuring point generally presents a gradually increasing trend with the increase of roughness value in village region, which is especially significant in the period of 18 to $36 \mathrm{~h}$. Compared with the condition of $n=0.06$, the corresponding maximum water depth at each measuring point increase by $0.09,0.19$, $0.25 \mathrm{~m}$, respectively under the condition of $n=0.08,0.10$ and 0.12 . In addition, at the same time, the flow velocity at PT1 and PT3 under the scenario of center-hollowed village region is relatively smaller, and the flow velocity at PT2 and PT4 under the scenario of center-hollowed village region is relatively larger. The flow velocity of each measuring point generally presents a gradually decreasing trend with the increase of roughness value in village region. Compared with the condition of $n=0.06$, the corresponding maximum flow velocity at each measuring point decrease by $0.11,0.19,0.24 \mathrm{~m} / \mathrm{s}$, respectively under the condition of $n=0.08,0.10$ and 0.12 . Overall, the effects of the center-hollowed village regions condition on water depth and flow velocity are very obvious. For different conditions of roughness value in village regions, the effects on water depth near the village are smaller, and the effects on flow velocity near 
the village are larger, especially for PT1 and PT3 in the direction of the water flow.

The water depth and velocity distribution near Fanji village with the roughness value of 0.06 and 0.12 during the flood peak are shown in Figure 7. From the figure, because of the influence of different roughness values of village regions, the water depth of village regions gradually increased with the increase of the roughness, while the flow velocity gradually decreased. When the roughness $n=0.06$, the water depth is $2.81 \mathrm{~m}$, and the flow velocity is $0.40 \mathrm{~m} / \mathrm{s}$; When the roughness $n=0.12$, the water depth is largest and the flow velocity is smallest. The maximum water depth is $2.93 \mathrm{~m} / \mathrm{s}$, the minimum flow velocity is $0.32 \mathrm{~m} / \mathrm{s}$.

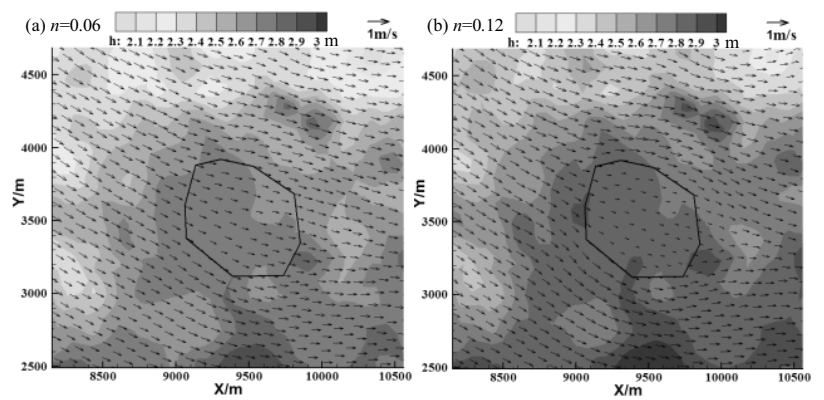

Figure 7. Distributions of velocity and water depth around a village during the flood peak.

\section{Conclusions}

In this paper a 2-D hydrodynamic model was set up and verified, and the process of overbank floods routing in typical floodplains of LYR was simulated. The effects of different roughness values of village regions on calculation results were analyzed. The analysis results show that center-hollowed village regions and different roughness values have significant effects on the calculation results. Specifically, the water depth under the scenario of center-hollowed village region is largest, with an increase in the maximum water depth of $0.57 \mathrm{~m}$; the maximum water depth under $n=0.12$ is $0.25 \mathrm{~m}$ greater than that under $n=0.12$, with the corresponding reduction value in velocity of $0.24 \mathrm{~m} / \mathrm{s}$. In terms of practical engineering problems, the treatment method and roughness value for village regions should be considered according to the actual conditions.

\section{Acknowledgement}

This work was financially supported by the Natural Science Foundation of China (No. 51379156), the National Nonprofit Research Program of China (No. 201401038) and the Science and Technology Research Project of the Education Department of Henan Province (No. 14A570001).

\section{References}

1. H. Wang, C. Zhou, Y. Wu, Q. Wan, 2-D flood simulation of the lower Yellow River from Huayuankou to Jiahetan. Advances in Water Science, 13, 215-222 (2002).

2. D. Li, Y. Lin, Y. Xu, Z. Zhou, Numerical model of flood propagation of rivers and flood detention basin. Journal of Tianjin University, 42, 47-55 (2009).

3. D. Sun, X. Liao, P. Wang, X. Zhang, X. Liu, Influence of productive embankment on river flooding by 2-D numerical simulation. Journal of Hydrodynamics (Ser. A), 22, 24-30 (2002).

4. D. Yu, S. N. Lane, Urban fluvial flood modelling using a two-dimensional diffusion-wave treatment, part 2: development of a sub-grid-scale treatment. Hydrological Processes, 20, 1567-1583 (2006).

5. M. S. Horritt, P. D. Bates, M. J. Mattinson, Effect of mesh resolution and topographic representation in 2D finite volume models of shallow water fluvial flow. Journal of Hydrology, 329, 306-314 (2006).

6. V. Caleffi, A. Valiani, A. Zanni, Finite volume method for simulating extreme flood events in natural channels. Journal of Hydraulic Research, 41, 167-177 (2003).

7. P. D. Bates, M. D. Wilson, M. S. Horritt, D. C. Mason, N. Holden, A. Currie, Reach scale floodplain inundation dynamics observed using airborne Synthetic Aperture Radar imagery: Data analysis and modelling. Journal of Hydrology, 328, 306-318 (2006).

8. J. Wang, R. Liu, A comparative study of finite volume methods on unstructured meshes for simulation of 2D shallow water wave problems. Mathematics and Computers in Simulation, 53, 171184 (2000).

9. P. Brufau, M. E. Vázquez-Cendón, P. GarcíaNavarro, A numerical model for the flooding and drying of irregular domains. International Journal for Numerical Methods in Fluids, 39, 247-275 (2002). 